\title{
Single-step transepithelial ASLA (SCHWIND) with mitomycin-C for the correction of high myopia: long term follow-up
}

This article was published in the following Dove Press journal:

Clinical Ophthalmology

30 December 2014

Number of times this article has been viewed

\section{loannis M Aslanides \\ Panagiotis N Georgoudis \\ Vasilis D Selimis \\ Achyut N Mukherjee}

Emmetropia Mediterranean Eye Institute, Heraklion, Crete, Greece
Correspondence: loannis Aslanides Emmetropia Mediterranean Eye Institute, Plateia Eleftherias 44, Heraklion, Crete 7|20I, Greece $\mathrm{Tel}+302810226198$ $\mathrm{Fax}+302810343436$

Email i.aslanides@emmetropia.gr
Purpose: We wanted to compare the outcomes of single-step modified transepithelial photorefractive keratectomy (tPRK) termed a SCHWIND all surface laser ablation (ASLA) versus conventional alcohol-assisted photorefractive keratectomy (PRK) and laser-assisted in situ keratomileusis (LASIK) for the correction of higher myopia of 6.00 diopters (D) or more, in an area with high risk of haze due to high intensity of sunlight.

Methods: We used a prospective interventional cohort with matched retrospective control groups. Patients with $>6 \mathrm{D}$ myopia and $<3.5 \mathrm{D}$ of astigmatism were included. All treatments were performed with the SCHWIND Amaris system using aspheric ablation profiles. Mitomycin C was used in all PRK and ASLA cases. Outcomes were postoperative refraction, visual acuity, stability, and complications. The follow-up period was up to 12 months.

Results: In total, 101 eyes were included after exclusions. Mean preoperative spherical equivalent refraction was $-7.9 \mathrm{D},-8.2 \mathrm{D}$, and $-7.4 \mathrm{D}$ in the ASLA $(\mathrm{n}=41)$, PRK $(\mathrm{n}=29)$, and LASIK ( $\mathrm{n}=31$ ) groups. Mean postoperative spherical equivalent at 12 months postoperatively was -0.1 (standard deviation [SD]: 0.34), -0.2 (SD: 0.59), and -0.08 (SD: 0.36) in the ASLA, PRK, and LASIK groups, with $91.4 \%, 85.7 \%$, and $83.9 \%$ within $0.5 \mathrm{D}$ of target, respectively. Refractive outcomes and regression at 12 months did not vary among groups $(P>0.05)$. Mean $\log$ MAR (logarithm of the minimum angle of resolution) uncorrected distance visual acuity at 12 months was 0.00 (SD: 0.05), 0.06 (SD: 0.1), and 0.05 (SD: 0.09) in the ASLA, PRK, and LASIK groups, with significantly better vision in the tPRK group versus LASIK $(P=0.01)$ and PRK $(P=0.01)$ groups

Conclusion: ASLA (SCHWIND) tPRK with mitomycin C for high myopia demonstrates comparable refractive outcomes to LASIK and PRK, with relatively favorable visual acuity outcomes. There was no increased incidence of haze in the ASLA group.

Keywords: PRK, LASIK, transepithelial PRK, high myopia, ASLA, Mitomycin, epithelium

\section{Introduction}

Photorefractive keratectomy (PRK) is an established procedure for the refractive correction of myopia. However, postoperative haze following PRK is exacerbated in higher degrees of correction and was initially the limiting factor for this group. The subsequent development of laser-assisted in situ keratomileusis (LASIK) offered more rapid visual recovery, less pain, and less haze. However, LASIK treatment in high myopia results in considerably more depth of stromal intrusion, with concerns over biomechanical stability and increased risk of ectasia. The development of adjuvant mitomycin C (MMC) therapy as prophylaxis for haze demonstrates benefits in the refractive correction of high myopia and has resulted in a reappraisal of the role of PRK versus LASIK in this group. ${ }^{1-3}$ 
Transepithelial PRK (tPRK), wherein the epithelium is removed using excimer laser PTK prior to application of the stromal refractive treatment, is well described. ${ }^{4-11}$ More recently, a novel treatment modality utilizing excimer epithelial removal using a population-based epithelial profile rather than PTK epithelial removal has become available on the SCHWIND Amaris platform (SCHWIND eye-tech-solutions $\mathrm{GmbH}$, Kleinostheim, Germany) termed transepithelial all surface laser ablation (ASLA). Compared to alcohol-based or mechanical epithelial removal, transepithelial ablation has several potential differences, which may affect both refractive outcome and haze, and there is some evidence that singlestep tPRK may itself limit haze. ${ }^{710}$ Thus, outcomes in higher myopia ( $\geq 6.00$ diopters $[D]$ ), wherein haze is more common, may differ from outcomes of conventional alcohol-assisted or mechanical PRK, and this may be further enhanced through the use of MMC. Currently, there are no data available regarding transepithelial single-step ablation for higher myopia or related to MMC application. In this study, we assessed the efficacy, predictability, safety, stability, and clinical outcomes of this transepithelial therapy combined with adjunctive MMC use for the refractive correction of high myopia, compared to conventional PRK and LASIK. We also wanted to investigate whether the incidence of haze with the tPRK was any higher, especially as our institution is located in an area with high intensity and long duration of sunlight.

\section{Methods}

This was a comparative evaluation of a prospective cohort of highly myopic ( $-6 \mathrm{D}$ or more) patients undergoing ASLA tPRK, with two retrospective matched control groups undergoing LASIK and conventional alcohol-assisted PRK, respectively. MMC was used in all PRK and tPRK cases. Patients were recruited at Emmetropia Mediterranean Eye Institute, which is a refractive surgery institute in Crete, Greece, between July 2010 and June 2011, with minimum follow-up period of 1 year. Inclusion criteria for both the prospective intervention group and retrospective controls were age $>18$ years and myopic spherical equivalent (SE) refraction $>6 \mathrm{D}$, with $<3.5 \mathrm{D}$ of refractive or corneal astigmatism stable for more than 1 year. Prior to the recruitment, all suitable patients were consulted, informed about the risks and benefits of each technique, and were provided the choice of tPRK, PRK, or LASIK (if suitable). If their technique of choice was the tPRK, they were recruited for the study (prospective group). Exclusion criteria were abnormal or keratoconic topography, the presence of coexisting ocular pathology or previous surgery, inflammatory or infectious corneal disease, or relevant systemic dermatologic or connective tissue disorders. The study conformed to the tenets of the Declaration of Helsinki. Patients in the prospective group were included subject to informed consent, and ethical approval was provided by the Emmetropia Mediterranean Eye Institute review board.

\section{Preoperative assessment}

Preoperative assessment included manifest and cycloplegic subjective refraction and autorefraction. Logarithm of the minimum angle of resolution (logMAR) visual acuity was assessed. Slit lamp biomicroscopy, mydriatic fundoscopy, and assessment of intraocular pressure and mesopic pupil diameter were performed. Preoperative slit-scan corneal topography (Orbscan IIz; Bausch \& Lomb, Rochester, NY, USA), corneal wavefront analysis (Keratron Scout Topographer; Optikon SpA, Rome, Italy), and total ocular wavefront measurement (Hartmann-Shack Aberrometer/ ORK-Wavefront Analyzer; SCHWIND eye-tech-solutions) were also carried out.

\section{Surgical technique}

All treatments were performed using the SCHWIND Amaris 750 excimer laser platform (SCHWIND eye-tech-solutions). This uses a $193 \mathrm{~nm}, 0.54 \mathrm{~mm}$ super-Gaussian profile flying-spot laser with pseudorandom thermal optimization. Preoperative anesthesia was achieved with proparacaine eye drops instilled 3 times starting 15 minutes before surgery. Povidone-iodine (5\%) solution was instilled prior to application of lid adhesive drape and speculum.

In the tPRK group, the profile outlined was utilized, with custom epithelial profile and reverse application. All treatments were aspheric aberration-neutral non-wavefront-guided profiles. Excimer laser application was preceded by standardized wet sponge application; a Merocel sponge (Medtronic Inc, Minneapolis, MN, USA) dipped in balanced salt solution was applied with three slow painting movements on the corneal surface to avoid uneven wetting and thus uneven ablation. Single-step laser delivery was carried out immediately afterward, and the cornea was then cooled with $20 \mathrm{~mL}$ chilled balanced salt solution. MMC $(0.02 \%)$ was immediately applied for 30 seconds using a damp Merocel sponge, then copiously irrigated, and dried. One drop of topical ketorolac $(0.5 \%)$ and one drop of ofloxacin $(0.3 \%)$ were subsequently instilled, and a bandage contact lens (Frequency Aspheric; CooperVision, Pleasanton, CA, USA) was inserted. After surgery, all eyes received topical ofloxacin $(0.3 \%)$ qid until removal of the contact lens, dexamethasone $(0.1 \%)$ drops qid reducing over 12 weeks, and artificial teardrops qid for 3 months. 
Cases undergoing PRK underwent the same regime, except that epithelial removal was carried out by application of $20 \%$ alcohol for 20 seconds in an $8.5 \mathrm{~mm}$ well, followed by rinsing and epithelial removal. Wet sponge application was not used. Excimer ablation was carried out with an aspheric aberrationneutral profile. MMC application and postoperative regime was the same as for the transepithelial PRK protocol.

LASIK cases had a preoperative apraclonidine $(0.5 \%)$ drop (to prevent hyperemia and hemorrhage) in addition to the anesthetic. A microkeratome (Moria M2; Moria SA, Antony, France) was used with a disposable head for intended flap thickness of $90 \mu \mathrm{m}$ in all cases, with a superior hinge.

\section{Postoperative assessment}

Patients attended for follow-up postoperatively at day 1 and day 3 , at 1 week, and at 1, 3, 6, and 12 months. Parameters assessed were slit lamp biomicroscopy, LogMAR visual acuity, autorefraction (1-week visit onward), and subjective refraction (1-month visit onward). Postoperative haze for PRK groups was graded clinically using the Fantes scale. ${ }^{12}$

\section{Analysis}

All statistical analyses were performed using Microsoft Excel (Microsoft Corporation, Redmond, WA, USA). Postoperative and temporal changes were compared using paired $t$-tests. A $P$-value $<0.05$ was considered statistically significant. Results were reported using standard graphs for refractive surgery outcomes. Mean uncorrected distance visual acuity (UDVA) was used to assess efficacy, and preoperative versus postoperative histogram was plotted. Safety was evaluated by the preoperative to postoperative change in the lines of corrected distance visual acuity (CDVA) and safety index of mean postoperative CDVA/mean preoperative CDVA. Accuracy was determined by comparing the attempted against the achieved change in SE. Stability was reported in terms of comparison of refractive outcome at postoperative time points.

\section{Laser treatment parameters}

Ablation profile planning was carried out using the integrated optimized refractive keratectomy (ORK)-CAM software. Mean planned maximum ablation depth was $159.8 \mu \mathrm{m}$ (SD: $14 \mu \mathrm{m}$; range: 100-185 $\mu \mathrm{m}$ ) in the transepithelial group. This ablation value includes the epithelium; thus, subtracting the expected central epithelial thickness of $55 \mu \mathrm{m}$, this corresponds to a mean stromal ablation depth of $104.7 \mu \mathrm{m}$, ranging from 45 to $130 \mu \mathrm{m}$. Planned ablation in the control groups was $111 \mu \mathrm{m}$ (SD: $14.4 \mu \mathrm{m}$; range: $90-136 \mu \mathrm{m}$ ) in the PRK group and $113 \mu \mathrm{m}$ (SD: $13.2 \mu \mathrm{m}$; range: 79-139 $\mu \mathrm{m}$ ) in the LASIK group. Based on the measured corneal thickness, this resulted in a mean intended residual central corneal thickness of $431 \mu \mathrm{m}$ (SD: $31.1 \mu \mathrm{m}$; range: $388-505 \mu \mathrm{m}$ ) in the transepithelial group and $419 \mu \mathrm{m}$ (SD: $28 \mu \mathrm{m}$; range: $370-475 \mu \mathrm{m})$ in the PRK group. In the LASIK group, the preablation stromal bed thickness, measured intraoperatively by ultrasonography after flap creation and lift, was used to calculate the residual stromal bed above the flap, the mean of which was $331.9 \mu \mathrm{m}$ (SD: $26.0 \mu \mathrm{m}$; range: $282-386 \mu \mathrm{m})$, significantly less than in the PRK groups $(P<0.001)$.

The desired optical zone was $6.5 \mathrm{~mm}$; however, in some cases in which the predicted ablation depth and preoperative corneal thickness resulted in suboptimal residual corneal thickness, the diameter was reduced. In most cases, this was reduced to $6 \mathrm{~mm}$ and, in a few cases, to a minimum of $5.75 \mathrm{~mm}$. Mean optical zone was thus $6.03 \mathrm{~mm}$ (SD: $0.19 \mathrm{~mm}$; range: $5.75-6.50 \mathrm{~mm}$ ) in the transepithelial group, $6.10 \mathrm{~mm}$ (SD: $0.15 \mathrm{~mm}$; range: $5.75-6.50 \mathrm{~mm}$ ) in the PRK group, and $6.27 \mathrm{~mm}$ (SD: $0.22 \mathrm{~mm}$; range: $5.75-6.5 \mathrm{~mm}$ ) in the LASIK group and thus, slightly although significantly, more in the LASIK group $(P<0.001)$.

All PRK patients underwent standardized MMC (0.02\%) treatment for 30 seconds immediately following laser ablation. There were no perioperative complications, and all recruited patients underwent the planned treatment according to protocol.

\section{Results}

The study consisted of 101 eyes of 64 patients. There were 41 eyes of 27 patients in the tPRK group, 29 eyes of 20 patients in the standard PRK group, and 31 eyes of 17 patients in the LASIK group included in the study after exclusions. In patients with unilateral study inclusion, the contralateral eye had lesser myopia outside the study limits or other refractive treatments. In the prospective tPRK group, three patients (six eyes) were lost to follow-up at the final study visit at 12 months due to noncompliance or moving out of the area, with one patient (two eyes) lost at 6 months. All cases selected for the refraction-matched retrospective control groups had follow-up lasting up to at least 1 year.

Mean preoperative SE and CDVA for TPRK, PRK, and LASIK groups had no significant difference (Table 1). Mean age, central pachymetry, mean keratometry, mean optical zone, and mean stromal ablation depth are shown in Table 1. Among these factors, the only significant differences were for age and central corneal thickness between tPRK and LASIK control groups. This was expected in this retrospective control group because for higher myopic corrections, 
Table I Reverse single-step tPRK for high myopia: baseline values and operative factors compared to PRK and LASIK control groups

\begin{tabular}{|c|c|c|c|c|c|}
\hline Baseline preoperative values & tPRK & PRK & LASIK & $\begin{array}{l}\text { P-value } \\
\text { (tPRK vs PRK) }\end{array}$ & $\begin{array}{l}\text { P-value } \\
\text { (tPRK vs LASIK) }\end{array}$ \\
\hline Number of eyes & 41 & 29 & 31 & & \\
\hline Mean preoperative SE $(D \pm S D)$ & $-7.89(1.24)$ & $-8.25(1.72)$ & $-7.41(1.35)$ & 0.28 & 0.13 \\
\hline Mean preoperative logMAR CDVA $( \pm S D)$ & $0.032(0.05)$ & $0.04(0.07)$ & $0.03(0.06)$ & 0.58 & 0.97 \\
\hline Mean age (years) & $27(6)$ & $27(7)$ & $31.3(10)$ & 0.75 & 0.03 \\
\hline Central pachymetry $(\mu \mathrm{m})$ & $536(30)$ & $530(29)$ & $551(23)$ & 0.387 & 0.02 \\
\hline Mean keratometry $(D)$ & $44.25(1.44)$ & $44.02(1.43)$ & $43.3(3.7)$ & 0.49 & 0.20 \\
\hline Mean optical zone (mm) & $6.03(0.19)$ & $6.10(0.15)$ & $6.27(0.22)$ & 0.14 & $<0.001$ \\
\hline Stromal ablation depth $(\mu \mathrm{m})$ & $105(14)$ & III (I4) & $113(13)$ & 0.06 & $<0.001$ \\
\hline
\end{tabular}

Abbreviations: CDVA, corrected distance visual acuity; D, diopters; LASIK, laser-assisted in situ keratomileusis; logMAR, logarithm of the minimum angle of resolution; PRK, photorefractive keratectomy; SD, standard deviation; SE, spherical equivalent; tPRK, transepithelial PRK; vs, versus.

we only perform LASIK in thicker corneas with greater age to reduce the risk of ectasia.

\section{Visual acuity efficacy and safety}

At 12 months, the mean $\log$ MAR UDVA was 0.00 (range: -0.14 to 0.15 ; SD: 0.05 ; Snellen vision $20 / 20$ ) in the tPRK group, 0.06 (range: -0.08 to 0.3 ; SD: 0.1 ; Snellen vision: $20 / 23$ ) in the PRK group, and 0.05 (range: 0.0 to 0.39 ; SD: 0.09; Snellen VA: 20/22) in the LASIK group. At the 12-month time point, UDVA was significantly better in the tPRK group than in the PRK $(P=0.01)$ and $\operatorname{LASIK}(P=0.008)$ groups. The proportion of patients achieving UDVA of 20/20 or better at 12 months was $77.1 \%$ and $60.7 \%$ in the tPRK and PRK groups, respectively, while only $48.3 \%$ achieved this level of vision in the LASIK group (Figure 1). No eye lost two or more lines of vision in the tPRK group (Figure 2). The visual outcomes are summarized in Table 2.

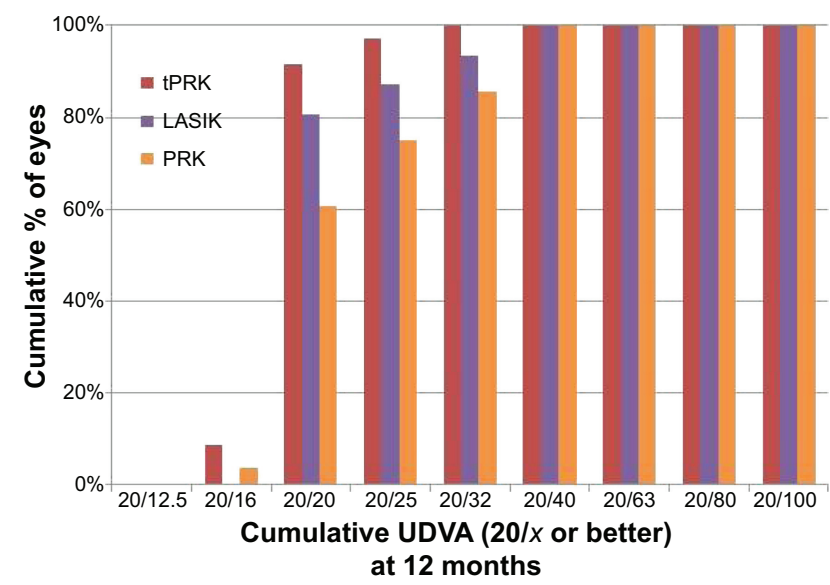

Figure I Cumulative proportion of eyes achieving Snellen visual acuity targets at 12 months after transepithelial photorefractive keratectomy (tPRK), laser-assisted in situ keratomileusis (LASIK), and photorefractive keratectomy (PRK).

Abbreviations: LASIK, laser-assisted in situ keratomileusis; PRK, photorefractive keratectomy; tPRK, transepithelial PRK; UDVA, uncorrected distance visual acuity.

\section{Refractive outcome and stability}

The mean SE at 12 months was $-0.10 \mathrm{D}$ (SD: $0.34 \mathrm{D}$ ) in the tPRK, -0.2 D (SD: 0.59 D) in the PRK, and -0.08 D (SD: $0.36 \mathrm{D}$ ) in the LASIK groups (Figure 3). The proportion of eyes within 0.5 and $1.0 \mathrm{D}$ of target are shown in Table 2. There was no significant difference between the groups. Astigmatic outcome was accurate and did not vary between groups (Figure 4). Linear regression analysis of achieved versus attempted refraction for each technique in terms of predictability (Figure 5) revealed a coefficient $\left(R^{2}\right)$ of 0.9205 in the tPRK group, 0.8193 in the PRK group, and 0.9239 in the LASIK group. The linear regression slope was 0.939 in the tPRK, 0.898 in the PRK, and 1.035 in the LASIK groups, all values being close to 1.00 and demonstrating validity of the nomogram at higher powers for each technique. There was no significant difference in regression at 12 months between groups (Figure 6).

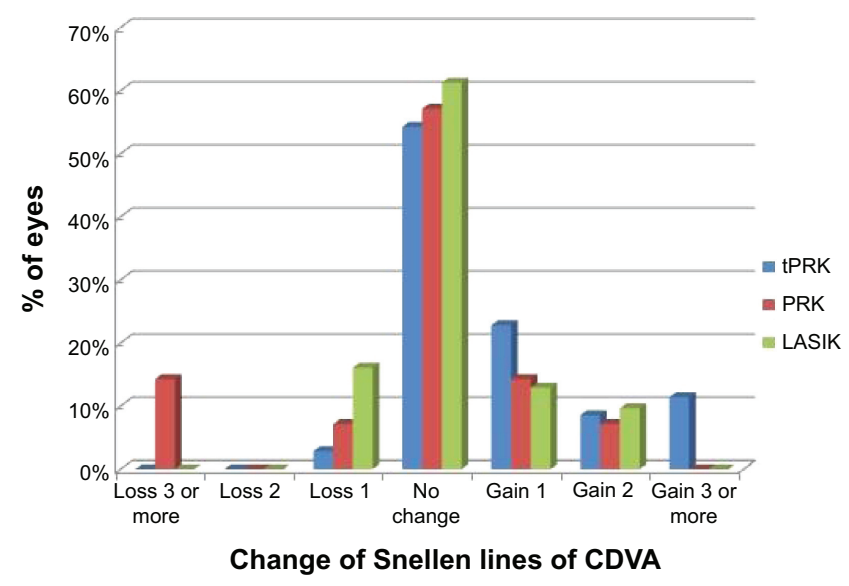

Figure 2 Proportion of eyes gaining or losing best-corrected Snellen visual acuity at 12 months after transepithelial photorefractive keratectomy, laser-assisted in situ keratomileusis, and photorefractive keratectomy.

Abbreviations: CDVA, corrected distance visual acuity; LASIK, laser-assisted in situ keratomileusis; PRK, photorefractive keratectomy; tPRK, transepithelial PRK. 


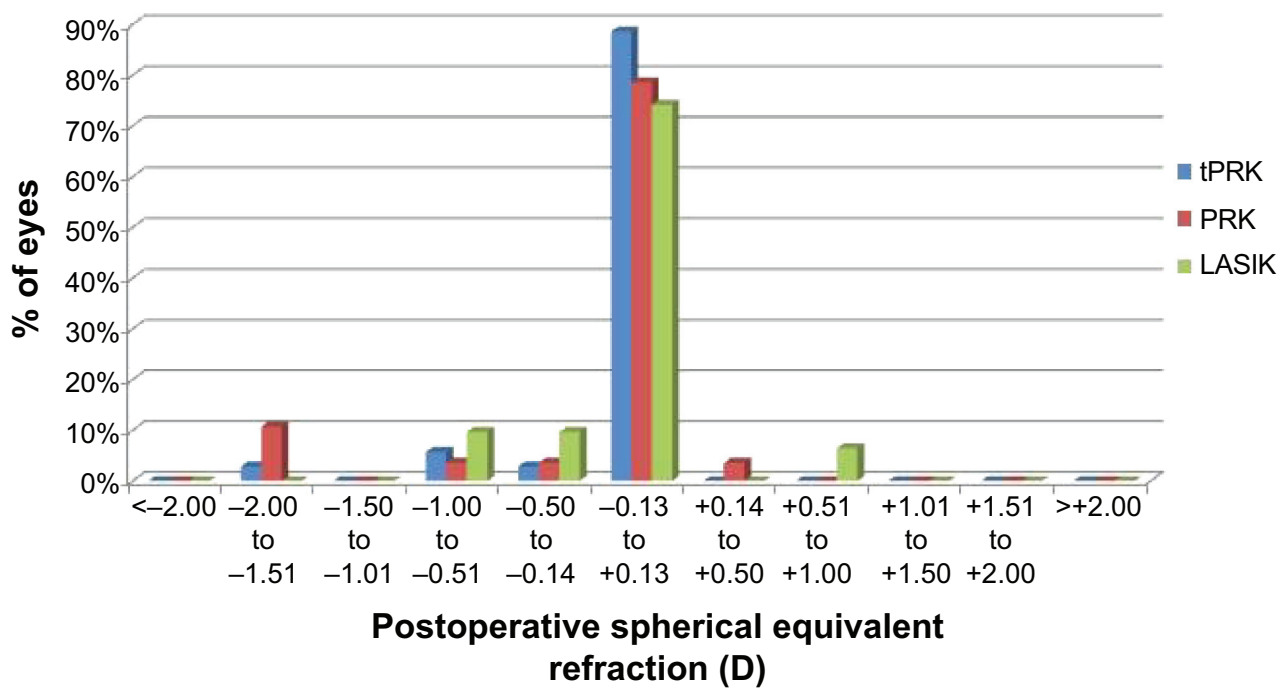

Figure 3 Postoperative spherical equivalent subjective refraction in eyes with plano target refraction at 12 months after transepithelial photorefractive keratectomy (tPRK), laser-assisted in situ keratomileusis (LASIK), and photorefractive keratectomy (PRK).

\section{Haze}

Haze in the PRK groups was clinically graded using the Fantes scale at postoperative visits. ${ }^{12}$ In the tPRK group, at 3 months, 15 (37\%) of the eyes had some clinically apparent (although not visually significant) haze, with a mean score of 0.47 (SD: 0.64 , range: $0-2$ ). Of the affected eyes, 12 $(29.2 \%)$ had grade 1 haze, and $3(7.3 \%)$ had grade 2 haze. By 6 months, this had reduced to 9 (22\%) eyes with haze, of which the majority had grade 1 visually insignificant haze, 2 (5\%) had grade 2 haze, and the mean haze score was 0.30 (SD: 0.57; range: 0-2). By 12 months, haze had regressed almost completely, with only one case demonstrating minimal, visually insignificant haze (less than grade 1). In the standard PRK group, at 3 months, six (21\%) eyes had some haze, with mean score of 0.54 (SD: 0.66; range: 0-2). By
6 months, this had reduced to five (17\%) eyes, all at grade 1 . There was no residual haze at 12 months. There was no significant difference between the tPRK and PRK groups in this regard ( $P>0.05$, all measures).

\section{Discussion}

The tPRK in this study differs from mechanical, alcoholassisted, and traditional PTK/PRK in being a single-step treatment, with reverse application of the refractive profile occurring prior to the epithelial ablation profile. The treatment assessed thus differs from conventional PRK in a number of aspects, and we sought to evaluate whether this affects refractive outcomes and haze formation in high myopia., ${ }^{70,13}$

In this study, we found that single-step tPRK appears to have predictable refractive outcomes for higher degrees

Table 2 Reverse single-step transepithelial PRK for high myopia: visual and refractive outcomes compared to PRK and LASIK control groups

\begin{tabular}{|c|c|c|c|c|c|}
\hline & tPRK & PRK & LASIK & $\begin{array}{l}\text { P-value } \\
\text { (tPRK vs PRK) }\end{array}$ & $\begin{array}{l}\text { P-value } \\
\text { (tPRK vs LASIK) }\end{array}$ \\
\hline \multicolumn{6}{|l|}{ Efficacy and safety at 12 months } \\
\hline Number of eyes & 35 & 28 & 31 & & \\
\hline Postoperative logMAR UDVA (SD) & $0.00(0.05)$ & $0.06(0.1)$ & $0.05(0.09)$ & 0.01 & 0.008 \\
\hline $20 / 25$ equivalent or better UDVA (\%) & 97.1 & 75.0 & 87.1 & 0.51 & 0.02 \\
\hline $20 / 20$ equivalent or better UDVA (\%) & 77.1 & 60.7 & 48.3 & 0.30 & 0.09 \\
\hline Loss of 2 or more lines CDVA (\%) & 0 & 14.3 & 0 & 0.03 & I \\
\hline \multicolumn{6}{|c|}{ Refractive outcomes 12 months postoperatively } \\
\hline Mean postoperative SE, D (SD) & $-0.10(0.34)$ & $-0.20(0.59)$ & $-0.08(0.36)$ & 0.4 & 0.72 \\
\hline$\%$ within $\pm 0.5 \mathrm{D}$ target & 91.4 & 85.7 & 83.9 & 0.68 & 0.45 \\
\hline$\%$ within $\pm 1.0 \mathrm{D}$ target & 97.1 & 89.3 & 100 & 0.31 & $\mathrm{I}$ \\
\hline
\end{tabular}

Abbreviations: CDVA, corrected distance visual acuity; D, diopters; LASIK, laser-assisted in situ keratomileusis; logMAR, logarithm of the minimum angle of resolution; SD, standard deviation; SE, spherical equivalent; PRK, photorefractive keratectomy; tPRK, transepithelial PRK; UDVA, uncorrected distance visual acuity; vs, versus. 


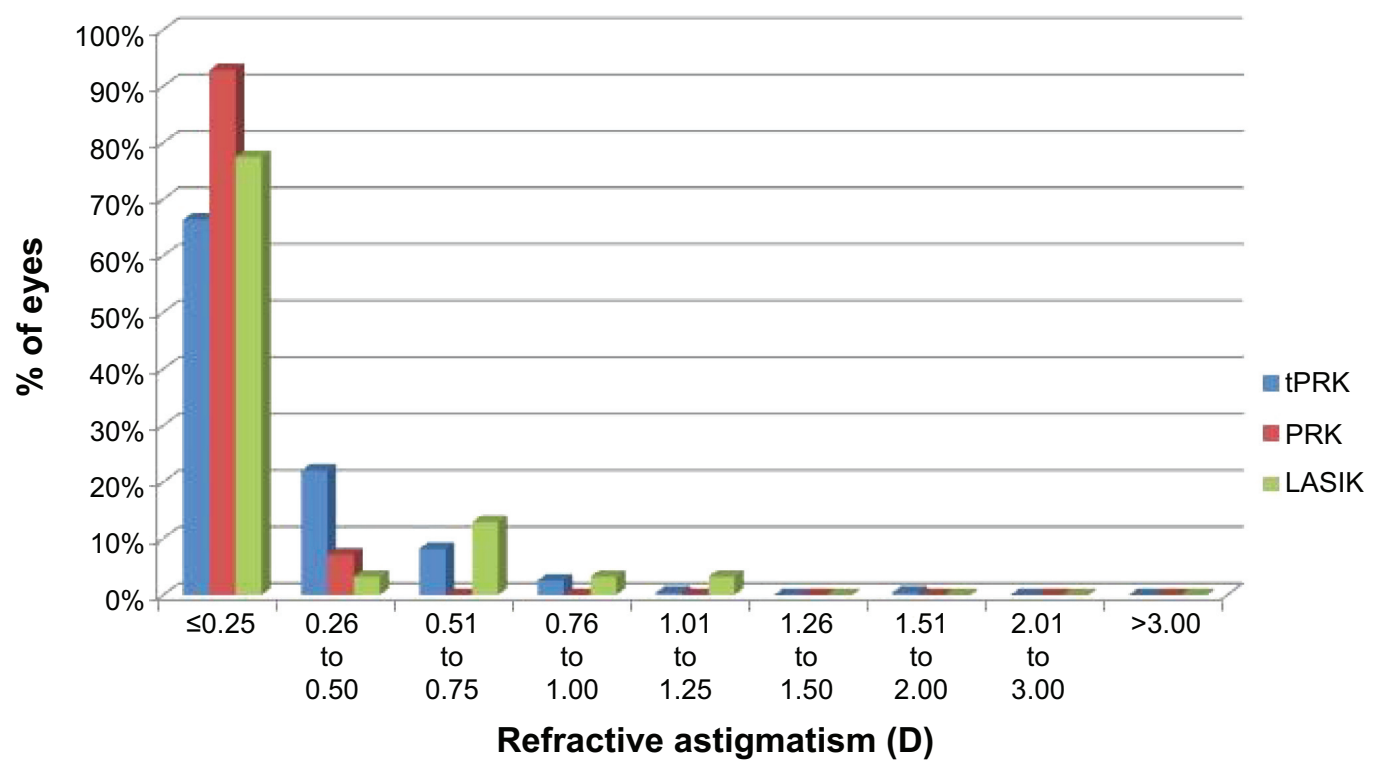

Figure 4 Postoperative subjective refractive astigmatism at 12 months after transepithelial photorefractive keratectomy (tPRK), laser-assisted in situ keratomileusis (LASIK), and photorefractive keratectomy (PRK).
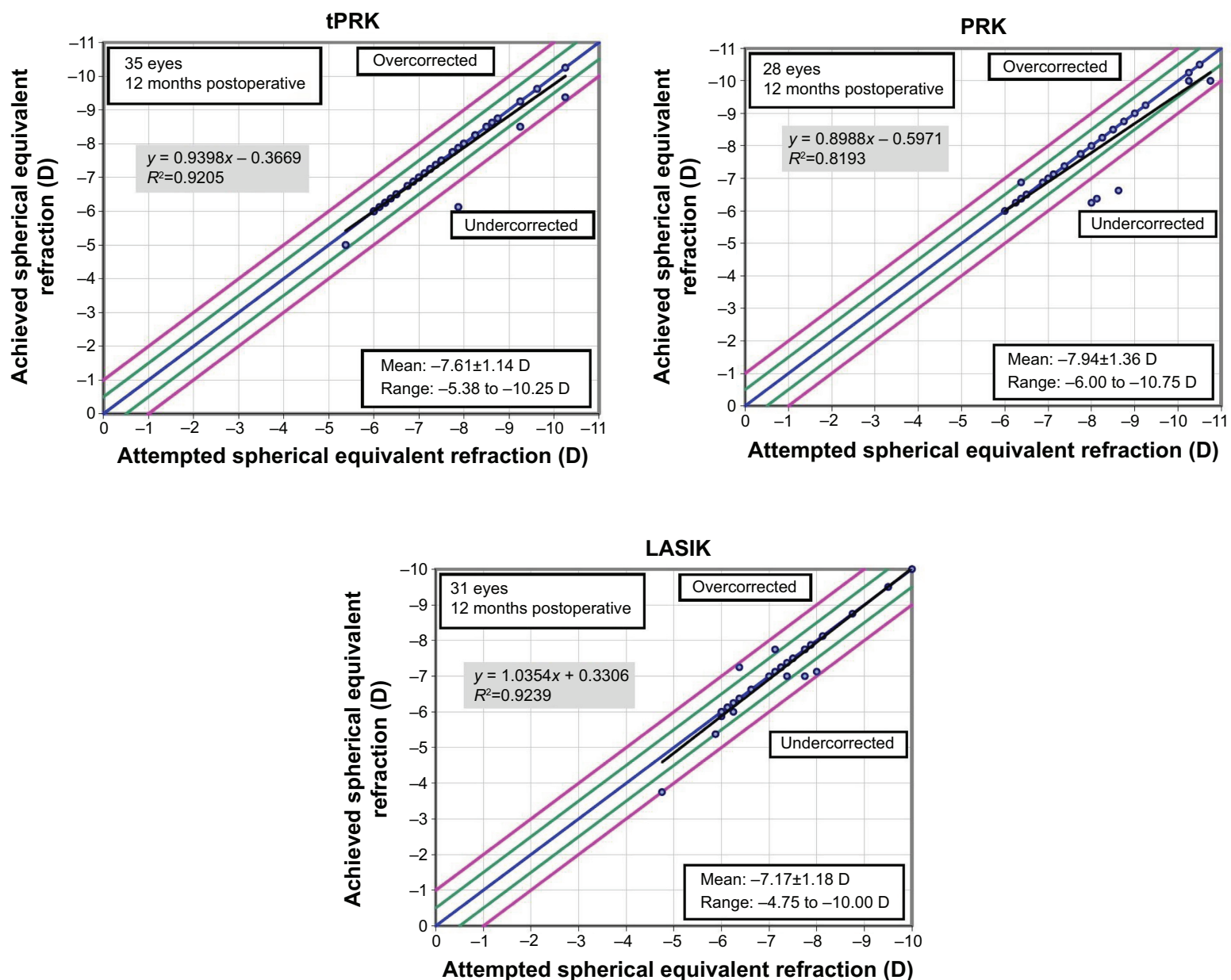

Figure 5 Postoperative achieved vs attempted spherical equivalent refraction at 12 months after transepithelial photorefractive keratectomy (tPRK), laser-assisted in situ keratomileusis (LASIK), and photorefractive keratectomy (PRK).

Note: The dots within the green lines indicate patients that achieved spherical equivalent (SE) within $\pm 0.5 \mathrm{D}$; and the dots within the purple lines indicates the patients that achieved SE within $\pm I .0 \mathrm{D}$ 

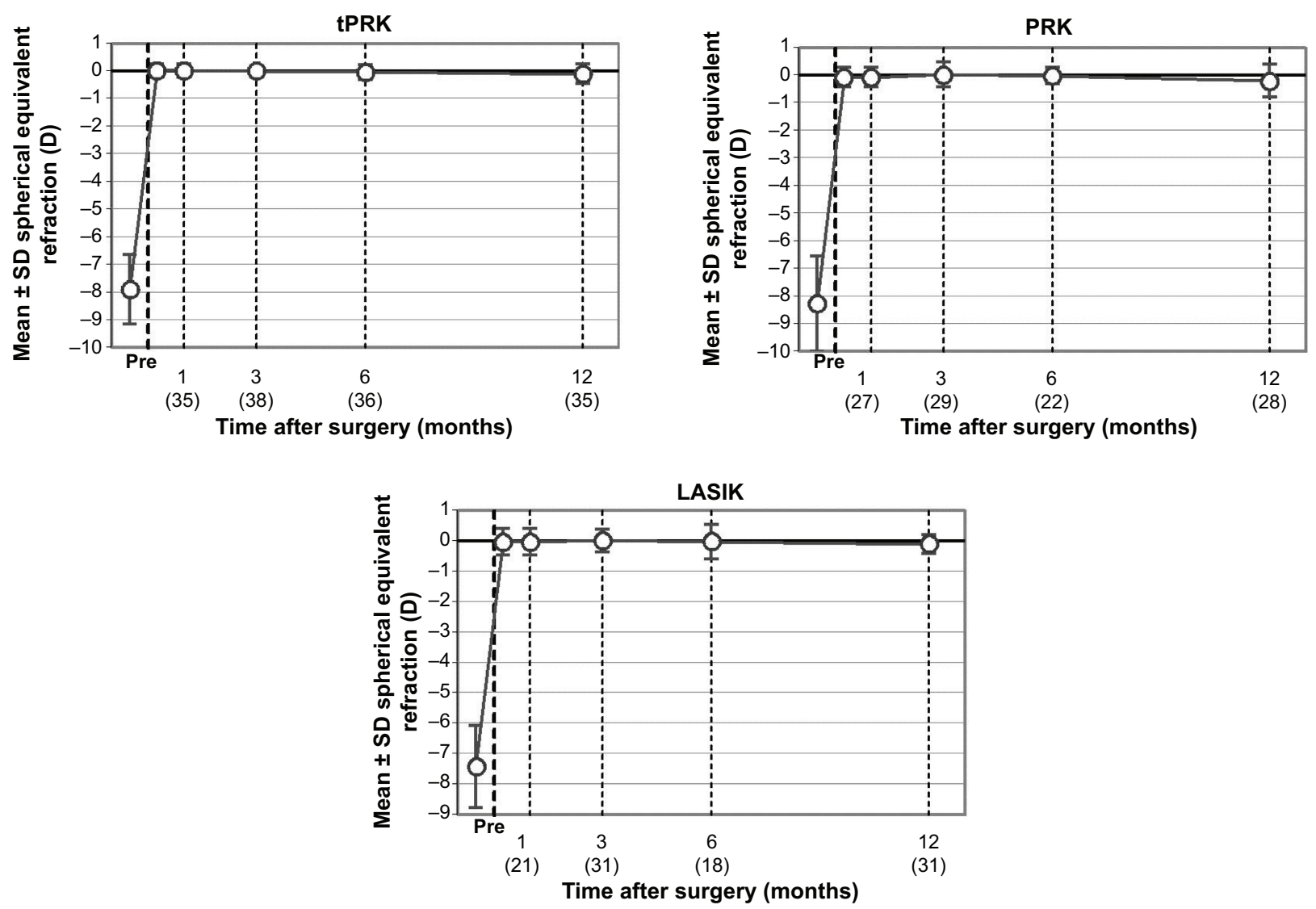

Figure 6 Temporal stability of spherical equivalent refractive correction at postoperative time points after transepithelial photorefractive keratectomy (tPRK), laser-assisted in situ keratomileusis (LASIK), and photorefractive keratectomy (PRK).

Notes: Numbers in parenthesis are the patients that attended for follow-up at the specific time point. The circles indicate mean SE and the error bars indicate SD values. Abbreviations: Pre, preoperative; SD, standard deviation; SE, spherical equivalent.

of correction. The main disadvantage of any transepithelial therapy is the potential variability in epithelial thickness and thickness distribution, which may theoretically affect refractive outcomes. Our data do not support this notion, with no evidence of inferior outcomes, compared to both standard PRK and LASIK approaches, in this study. Although this potential source of residual refractive error would be expected to be more relevant for smaller corrections, current evidence in the literature does not suggest this to be the case either. ${ }^{7,10,13}$

We have also recently found reduced haze formation compared to alcohol-assisted PRK using single-step tPRK for lower degrees of correction. ${ }^{7}$ In the current study, our protocol included the routine use of MMC, given the expected higher risk of haze with deeper ablations and the fact that the study was conducted in the island of Crete, an area with high intensity of sunlight. Although temperature and sunlight duration do confer clinically relevant difference to the outcomes of LASIK, ${ }^{14}$ a study by Nagy et al demonstrated that exposure to ultraviolet-B light increases the incidence of post-PRK haze. ${ }^{15}$ In our cohort, haze was not a significant limiting factor in this series; although a small proportion of cases had clinically identifiable haze in both the tPRK and the PRK groups, this was not visually limiting in any case.

With regard to ectasia risk and the choice of tPRK over LASIK for higher degrees of myopia, we assessed residual stromal bed thickness, which ranged from 333 to $450 \mu \mathrm{m}$. The creation of LASIK flaps, even with the use of a femtosecond laser and an intended thickness of $110 \mu \mathrm{m}$, has a variation that can be up to approximately $150 \mu \mathrm{m} .{ }^{16}$ Subtracting this value from the initial corneal thickness in our group reveals that the mean residual thickness would be only $273 \mu \mathrm{m}$, and as many as $15 \%$ of eyes would have a residual bed thickness of less than $250 \mu \mathrm{m}$, considered unsafe. In higher myopic treatments, we prefer to maintain a residual thickness of $>300 \mu \mathrm{m}$, both for safety and to allow the possibility of future enhancement. Applying these criteria, we would not consider about half of the eyes in the tPRK group suitable for LASIK treatment.

Corneal rigidity is permanently reduced after both LASIK and PRK treatments, ${ }^{17}$ reducing the biomechanical stability of the cornea. Some restiffening may occur in the PRK group in 
the long term. Reinstein et $\mathrm{al}^{18}$ using a mathematical model to estimate the relative differences in postoperative stromal tensile strength after PRK, LASIK, and SMILE, report that after removal of $100 \mu \mathrm{m}$ of corneal stroma, the total stromal tensile strength would be $68 \%$ for PRK and $54 \%$ for LASIK.

Given the known limitations of higher corrections with LASIK treatment with regard to increased ablation depth and concern for ectasia, PRK may be a preferred treatment in many cases notwithstanding haze. Existing comparative data for PRK, laser-assisted subepithelial keratectomy (LASEK), and LASIK for the management of higher myopia suggest similar outcomes or slightly superior outcomes in LASIK, and a meta-analysis of these data has also shown superior outcomes in LASIK. ${ }^{19-21}$ The use of mitomycin has been shown to result in better outcomes in high myopia with PRK; however, there is a paucity of data comparing PRK with MMC to LASIK in this group. ${ }^{1,2,22,23}$ In the current cohort, there was no evidence of superior outcomes with LASIK. On the contrary, there was statistically significantly better, uncorrected vision at 12 months and a significantly higher proportion of eyes achieving 20/20 vision in the tPRK group compared to the LASIK group. This supports the findings of Wallau et al who compared MMC PRK and LASIK in fellow eyes with moderate myopia and found superior visual and refractive outcomes with PRK, while Randleman et al also showed similar outcomes. ${ }^{24,25}$

At present, the limited published data, including our own, on outcomes for single-step tPRK suggest slightly superior outcomes and less haze compared to other PRK techniques. ${ }^{7,10}$ None of the existing series have assessed higher myopia specifically, and there are no data regarding the adjuvant use of MMC. Luger et al compared conventional alcohol-assisted and single-step tPRK, in a cohort that included few higher myopes. ${ }^{13}$ Although not specifically assessed in their study, there was no suggestion of increased error with higher corrections.

The main limitation of this study was that although the tPRK group was prospectively recruited, the results were compared with retrospective matched groups, in a nonrandomized design. However, there were some practical limitations in this regard. With regard to comparison versus LASIK, we have highlighted the fact that many of these eyes were of questionable safety for LASIK and thus could not have been safely randomized.

In conclusion, notwithstanding the limitations, the current data suggest that ASLA tPRK with MMC is an accurate and safe option for the correction of higher degrees of myopia. Although a small study, within this cohort, there was an equivalence of visual and refractive outcomes compared to LASIK, which warrants further evaluation.

\section{Disclosure}

The authors report no conflicts of interest in this work.

\section{References}

1. Gambato C, Miotto S, Cortese M, Ghirlando A, Lazzarini D, Midena E. Mitomycin C-assisted photorefractive keratectomy in high myopia: a long-term safety study. Cornea. 2011;30(6):641-645.

2. Carones F, Vigo L, Scandola E, Vacchini L. Evaluation of the prophylactic use of mitomycin-C to inhibit haze formation after photorefractive keratectomy. J Cataract Refract Surg. 2002;28(12):2088-2095.

3. Talamo JH, Gollamudi S, Green WR, De La Cruz Z, Filatov V, Stark WJ. Modulation of corneal wound healing after excimer laser keratomileusis using topical mitomycin C and steroids. Arch Ophthalmol. 1991;109(8):1141-1146.

4. Muller LT, Candal EM, Epstein RJ, Dennis RF, Majmudar PA. Transepithelial phototherapeutic keratectomy/photorefractive keratectomy with adjunctive mitomycin-C for complicated LASIK flaps. J Cataract Refract Surg. 2005;31(2):291-296.

5. Hutchinson CB, Jeffrey JH. Comparison of mechanical and transepithelial debridement during photorefractive keratectomy. Ophthalmology. 1997;106:483-489.

6. Thomann UM, Schipper I. Customized transepithelial no-touch ablation as therapeutic option. J Cataract Refract Surg. 2010;36(7):1244-1245.

7. Aslanides IM, Padroni S, Mosquera SA, Ioannides A, Mukherjee A. Comparison of single-step reverse transepithelial all-surface laser ablation (ASLA) to alcohol-assisted photorefractive keratectomy. Clin Ophthalmol. 2012;6:973-980.

8. Kanitkar KD, Camp J, Humble H, Shen DJ, Wang MX. Pain after epithelial removal by ethanol-assisted mechanical versus transepithelial excimer laser debridement. J Refract Surg. 2000;16(5):519-522.

9. Buzzonetti L, Petrocelli G, Laborante A, et al. A new transepithelial phototherapeutic keratectomy mode using the NIDEK CXIII excimer laser. J Refract Surg. 2009;25(1 suppl):S122-S124.

10. Fadlallah A, Fahed D, Khalil K, et al. Transepithelial photorefractive keratectomy: clinical results. J Cataract Refract Surg. 2011;37(10): 1852-1857.

11. Pedrotti E, Sbabo A, Marchini G. Customized transepithelial photorefractive keratectomy for iatrogenic ametropia after penetrating or deep lamellar keratoplasty. J Cataract Refract Surg. 2006;32: 1288-1291.

12. Fantes FE, Hanna KD, Waring GO, Pouliquen Y, Thompson KP, Savoldelli M. Wound healing after excimer laser keratomileusis (photorefractive keratectomy) in monkeys. Arch Ophthalmol. 1990; 108(5):665-675.

13. Luger MH, Ewering T, Arba-Mosquera S. Consecutive myopia correction with transepithelial versus alcohol-assisted photorefractive keratectomy in contralateral eyes: One-year results. J Cataract Refract Surg. 2012;38(8):1414-1423.

14. Neuhaus-Richard I, Frings A, Görsch IC, et al. Do outside temperature and sunlight duration influence the outcome of laser refractive surgery? Results from the Hamburg Weather Study. Clin Ophthalmol. 2014;8:1129-1137.

15. Nagy ZZ, Hiscott P, Seitz B, Schlötzer-Schrehardt U, Süveges I, Naumann GO. Clinical and morphological response to UV-B irradiation after excimer laser photorefractive keratectomy. Surv Ophthalmol. 1997;42(suppl 1):S64-S76.

16. Alió JL, Piñero DP. Very high-frequency digital ultrasound measurement of the LASIK flap thickness profile using the IntraLase femtosecond laser and M2 and Carriazo-Pendular microkeratomes. J Refract Surg. 2008;24(1):12-23. 
17. Hjortdal JØ, Møller-Pedersen T, Ivarsen A, Ehlers N. Corneal power, thickness, and stiffness: results of a prospective randomized controlled trial of PRK and LASIK for myopia. J Cataract Refract Surg. 2005;31(1):21-29.

18. Reinstein DZ, Archer TJ, Randleman JB. Mathematical model to compare the relative tensile strength of the cornea after PRK, LASIK, and small incision lenticule extraction. J Refract Surg. 2013; 29(7):454-460.

19. Shortt AJ, Bunce C, Allan BDS. Evidence for superior efficacy and safety of LASIK over photorefractive keratectomy for correction of myopia. Ophthalmology. 2006;113(11):1897-1908.

20. Talamo JH. By Hersh et al PRK versus LASIK for moderate to high myopia. Ophthalmology. 1998;105(8):1522-1523.

21. Ghadhfan F, Al-Rajhi A, Wagoner MD. Laser in situ keratomileusis versus surface ablation: visual outcomes and complications. J Cataract Refract Surg. 2007;33(12):2041-2048.
22. Hashemi H, Taheri SMR, Fotouhi A, Kheiltash A. Evaluation of the prophylactic use of mitomycin-C to inhibit haze formation after photorefractive keratectomy in high myopia: a prospective clinical study. BMC Ophthalmol. 2004;4(D):12.

23. Bedei A, Marabotti A, Giannecchini I, Ferretti C, Barabesi L. Hotorefractive keratectomy in high myopic defects with or without intraoperative mitomycin C: 1-year results. Eur J Ophthalmol. 2006;16(2):229-234.

24. Wallau AD, Campos M. One-year outcomes of a bilateral randomised prospective clinical trial comparing PRK with mitomycin C and LASIK Br J Ophthalmol. 2009;93(12):1634-1638.

25. Randleman JB, Perez-Straziota CE, Hu MH, White AJ, Loft ES, Stulting RD. Higher-order aberrations after wavefront-optimized photorefractive keratectomy and laser in situ keratomileusis. J Cataract Refract Surg. 2009;35(2):260-264.
Clinical Ophthalmology

\section{Publish your work in this journal}

Clinical Ophthalmology is an international, peer-reviewed journal covering all subspecialties within ophthalmology. Key topics include: Optometry; Visual science; Pharmacology and drug therapy in eye diseases; Basic Sciences; Primary and Secondary eye care; Patien Safety and Quality of Care Improvements. This journal is indexed on

Submit your manuscript here: http://www.dovepress.com/clinical-ophthalmology-journal

\section{Dovepress}

PubMed Central and CAS, and is the official journal of The Society of Clinical Ophthalmology (SCO). The manuscript management system is completely online and includes a very quick and fair peer-review system, which is all easy to use. Visit http://www.dovepress.com/ testimonials.php to read real quotes from published authors. 